\title{
DEGRADATION OF A-SI:H SOLAR CELLS: NEW EVIDENCE FOR A BULK EFFECT
}

\author{
N. Wyrsch and A. Shah \\ Institut de Microtechnique, Université de Neuchâtel, Rue Breguet 2, $\mathrm{CH}-2000$ Neuchâtel, Switzerland,
}

\begin{abstract}
Well defined sequences of non-uniform and uniform degradation steps are applied on several high quality bifacial $p$-i-n solar cells with different thicknesses of the intrinsic layer. This procedure allows one to separate interface and bulk effects in the degradation of a-Si:H solar cells, or more precisely to separate the influence of the modification of the internal electric field profile (due mainly to effect near the interface) from that of an increase in the deep defect density in the bulk; according to present data the latter is clearly responsible for the major part of a-Si:H cell degradation.
\end{abstract}

\section{INTRODUCTION}

One of the most important topics in the present research on a-Si:H concerns the problem of light-induced degradation of layers and of solar cells. In spite of many studies, it is still not clear which part of the cell (doped layers, interfaces, bulk of intrinsic layer) limit the stable efficiency. The problem is complicated by the fact that both internal field distribution as well as recombination centre profile control cell performance. Although a majority of the members of the a-Si:H community probably agrees with the opinion that light-induced degradation of solar cells is a bulk effect, and is due to an increase of the defect density within the whole of the intrinsic layer [1-3], but there are also some arguments in favour of an interface effect (at the $p / i$ and $n / i$ interfaces) [4].

In a recent study [5], we tried to separate interface and bulk effects of the degradation on the solar cell performance (open-voltage, short-circuit, fill-factor and efficiency) and, in particular, to check the significance of the internal field distribution for the saturated efficiency of the cell. In this context the following procedure was applied on cells of different thicknesses $(0.5$ to $2 \mu \mathrm{m})$ : We degraded both sides of bifacial cells one after the other, using strongly absorbed light (at $450 \mathrm{~nm}$, to deform the field) and then degraded them further using a uniformly absorbed light beam (at $650 \mathrm{~nm}$ ). Measurements of the $\mathrm{I}-\mathrm{V}$ curve, as well as of spectral response (SR) and of the internal field profile were performed before and after every degradation step. The deep defect density in the central part of the i-layer was monitored using a wavelength-dependent measurement of the $\mu \tau$ product by time-of-flight (TOF).

Although, in thick cells, saturated efficiencies were clearly controlled by the defect density created within the i-layer (see Fig. 1a), the saturated efficiency of the $0.5 \mu \mathrm{m}$ cell seems to be reached already after the first degradation step, namely after a strong blue light soaking through the p-layer (see Fig. 1b). However, since the generation profile under blue light extends well outside the interface region for this $0.5 \mu \mathrm{m}$ thick cell, a bulk effect for the degradation could not be ruled out by this experiment alone. One should also note that each degradation step was performed until a (near-) saturation of the cell performance could be observed.

To refine our analysis (for the $0.5 \mu \mathrm{m}$ thick cells), we devised a new strategy for the present study. The three different degradation steps, already mentioned above (with a well defined dose of light exposition), were,

a)

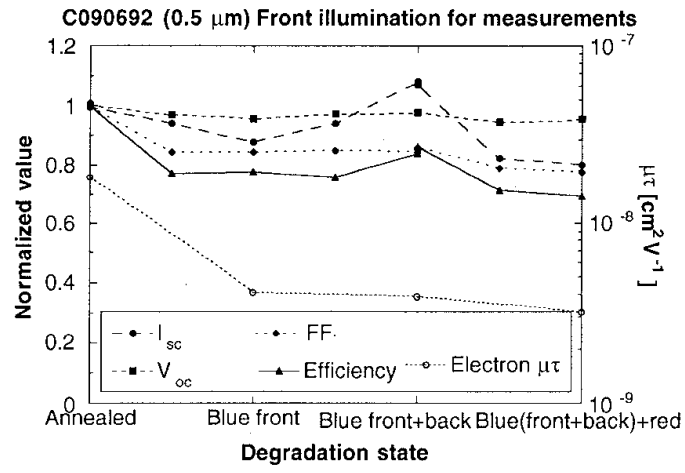

b)



Fig. 1: Normalised I-V characteristics (short-circuit current $I_{S C}$, open-circuit voltage $V_{O C}$, fill-factor FF and efficiency) and electron $(\mu \tau)$ e for (a) a $0.5 \mu \mathrm{m}$ thick cell, (b) a $1.5 \mu \mathrm{m}$ thick cell; measured under front illumination with an ELH lamp, in the annealed state and after each degradation step (as well as intermediate state). 
a)

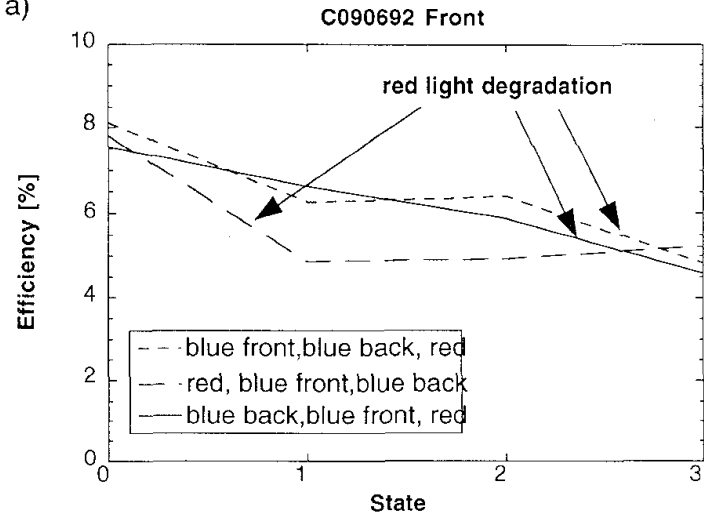

b)



Fig. 2: Efficiency of a $0.5 \mu \mathrm{m}$ thick bifacial cell (sample C090692) characterized in a solar simulator, with a front (a) and back (b) light exposure, after each step in three different sequences, composed each of three degradation steps. The same light-soaking time (100 hours) as well as the same light intensity were maintained for each individual step.

this time, applied in different sequences, for example:

(1) blue light soaking from the front (through the p-layer), blue light soaking from the back (through the n-layer) and then red light soaking (through the p-layer)

(2) blue light soaking from the back, blue light soaking from the front and then red light soaking

(3) red light soaking, blue light soaking from the frontand then blue light soaking from the back To achieve a better discrimination between the effect of the red and blue light degradation, the degradation doses (for each step) were kept much lower than in the preceding experiment [5]. Cell performance was recorded in-situ during each degradation step, as well as between the degradation steps in a solar cell simulator. Spectral response measurements were also performed to further analyse the evolution of the collection after each steps. Sequence (1), (2) and (3) were then compared to each other in order to determine the most harmful step for the degradation of the solar cell efficiency.
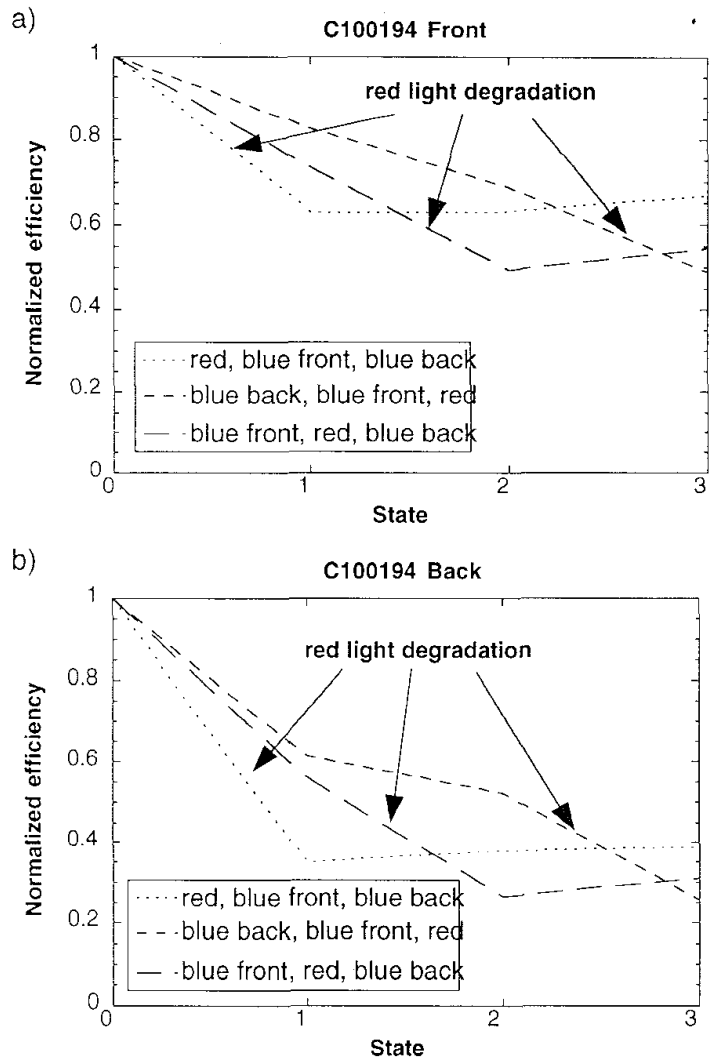

Fig. 3: Normalized efficiency of a $0.5 \mu \mathrm{m}$ thick bifacial cell (sample C100194) characterized in a solar simulator, with a front (a) and back (b) light exposure, after each step in three different sequences, composed each of three degradation steps. The same lightsoaking time (100 hours) as well as the same light intensity were maintained for each individual step.

\section{EXPERIMENTAL}

All cells used in this study were deposited with the VHF-GD technique described elsewhere [6]. The structure used consists of: a glass substrate coated with TCO, a $120 \AA$ thick p-window layer, a $60 \AA$ thick buffer layer, an approximately $0.5 \mu \mathrm{m}$ thick i-layer and a $300 \AA$ thick n-layers. A thick layer of ITO was employed to provide transparent back contact. The doped and intrinsic layers were deposited at a plasma excitation frequency of $70 \mathrm{MHz}$; the deposition rate for the $\mathrm{i}$-layer was $5 \AA^{-1}$

The cells were annealed at $180^{\circ} \mathrm{C}$ for 5 hours before every degradation sequence and then characterized on each side with $\mathrm{I}-\mathrm{V}$ measurements, on a double source Wacon solar simulator (under $100 \mathrm{mWcm}^{-2}$ ), and by determining spectral response at differe nt bias voltages, with and without bias light $\left(50 \mathrm{mWcm}^{-2}\right.$ white light). The initial efficiencies of the cells were between 8 and $8.5 \%$; these values were found to be lower than those of corresponding conventional cells because of the bifacial design (poor ITO reflectance properties). 
a)



b)

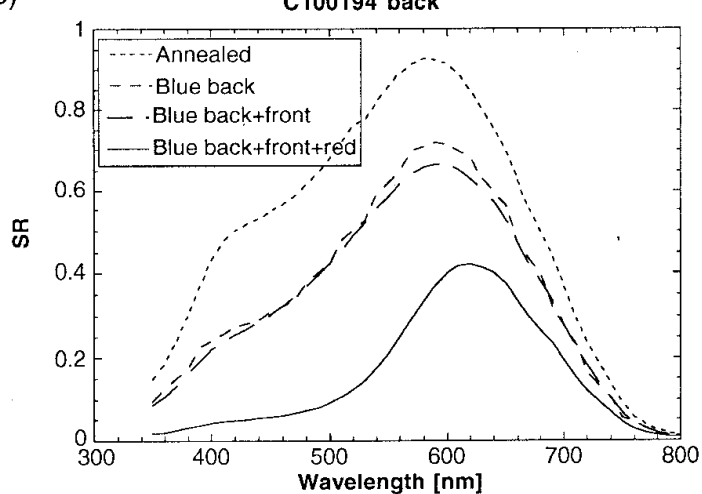

Fig. 4: Spectral response at $0 \mathrm{~V}$ under front (a) and back (b) illumination (with bias light) of a $0.5 \mu \mathrm{m}$ thick bifacial cell after each step of a degradation sequence (second sequence of Fig. 3).

For these light-soaking experiments, a $2000 \mathrm{~W}$ halogen lamp was used, filtered with a water filter and with interference filters with $50 \mathrm{~nm}$ bandwidth; wavelengths were $450 \mathrm{~nm}\left(75 \mathrm{mWcm}^{-2}\right)$ for the blue light and $650 \mathrm{~nm}$ $\left(170 \mathrm{mWcm}^{-2}\right)$ for the red light degradation. Each individual degradation step was carried out for 100 hours.

\section{RESULTS AND DISCUSSION}

Three different sequences of degradation steps were applied on two different $0.5 \mu \mathrm{m}$ thick diodes. The evolution of the normalized (to the initial annealed) efficiency is given on figures $2 a$ and 3 . As we can see, red light soaking of the cell (indicated with an arrow) is much more damaging than the other steps. Taking into account the fact that generation rate for red light was much smaller in the interface regions than for blue light, and that most of the recombination (under red light) occurs in the central part of the i-layer, we can easily conclude that creation of deep defects within the i-layer (far from the interfaces) critically control the cell efficiency. The same picture is observed when characterizing the cell under back-side illumination (see Fig. $2 b$ and $3 b$ ). Characterization of the cell performance a)

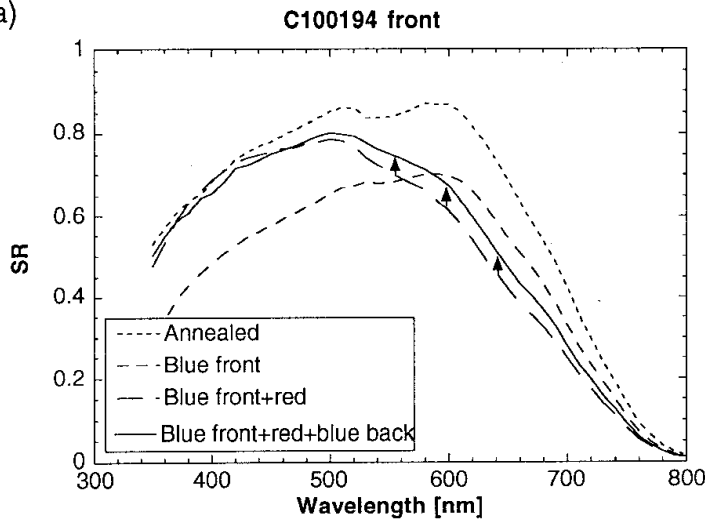

b)

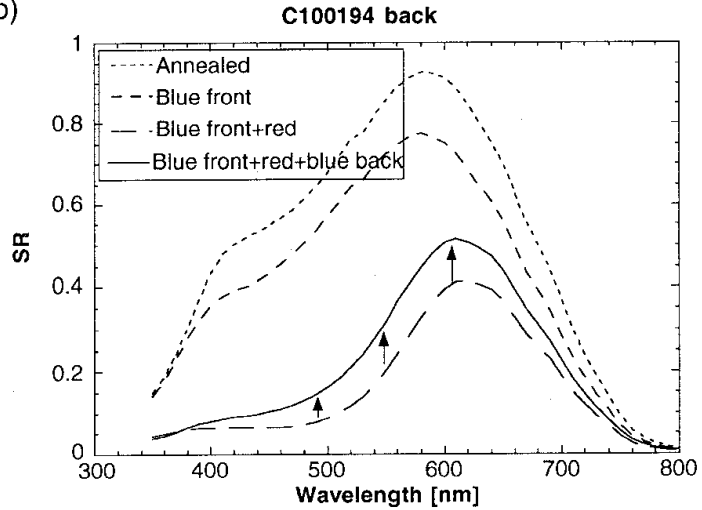

Fig. 5: Spectral response at $0 \mathrm{~V}$ under front (a) and back (b) illumination (with bias light) of a $0.5 \mu \mathrm{m}$ thick bifacial cell after each step of a degradation sequence (third sequence of Fig. 3). Enhancement of the response by back-side blue light is indicated by arrows.

under front or back illumination is (qualitatively) equivalent. Any degradation step affects, at the same time, the cell performances for front and back illumination, even though the latter is quantitatively more affected.

Thus, the final state of the cell is approximately given by the one reached after the red light degradation step. However, as we can observe on figures $2 a$ and $3 a$, further back side degradation with blue light, slightly improves the cell performance (this fact is also observed on an in-situ recording of the degradation). This effect is related to an enhancement of the field close to the $n / i$ interface, which improves hole collection, as is confirmed by spectral response measurement: Blue light soaking of the back-side of a red light soaked cell enhanced the red response for front illumination as well as the blue response for back illumination (see Fig. 4). Note, that blue light soaking of the back-side is only beneficial when done after the red light soaking.

Decrease of the performance during any degradation step is related to a decrease of both shortcircuit current $\mathrm{I}_{\mathrm{SC}}$ and fill-factor FF. However, in-situ recording of the I-V characteristics shows that FF drops faster than $I_{S C}$ at the beginning of every step. The origin of this difference remains so far unknown. 
Another interesting result of this study is the fact that the final behaviour of the cell does (almost) not depend on the degradation history, but rather on the accumulated time of light-soaking at the most damaging wavelength.

Spectral response measurements after each degradation step (see Figs. 4 and 5) are consistent with the I-V characteristics. The final state of the cell is obtained after the red light soaking step, independently of the previous degradation steps; responses of the cell after the first degradation step differ considerably from each other depending on the wavelength and the direction (front or back) of the light soaking used for that step. Fig. 4 offers a good illustration of the effect of "interface degradation" (by blue light soaking from both sides) as compared with "bulk degradation" (by red light soaking). The drop of the spectral response seen after the blue light soaking from both sides occurs for the full range of wavelengths and can be attributed to the reduction of the internal field (in the central part of the i-layer), whose profile becomes close to its final form and value after the red light soaking [5] (see [7] for details about the internal field measurement technique).

One should note that spectral response measurement must be performed with bias light in order to be compared with cell I-V characteristics. Spectral response curves measured without bias light (see Fig. 6) are determined by the internal field profile of the cell in the dark (see also Ref. [8]). The response without bias light always shows a strong decrease in the blue, even if the actual deterioration in the operating solar cell is in the red light region (compare Figs. 4a and 6). This can lead to a misinterpretation of the spectral response data, and is one of the reasons which lead some researchers to locate the part of the cell controlling the stable efficiency in the interfaces regions. On the other hand, as the internal field profile of the cell directly depends on the defect density in the i-layers, the spectral response in the dark is a good indicator of the degradation stage and can e.g. be used to verify the fully annealed state of the cell.

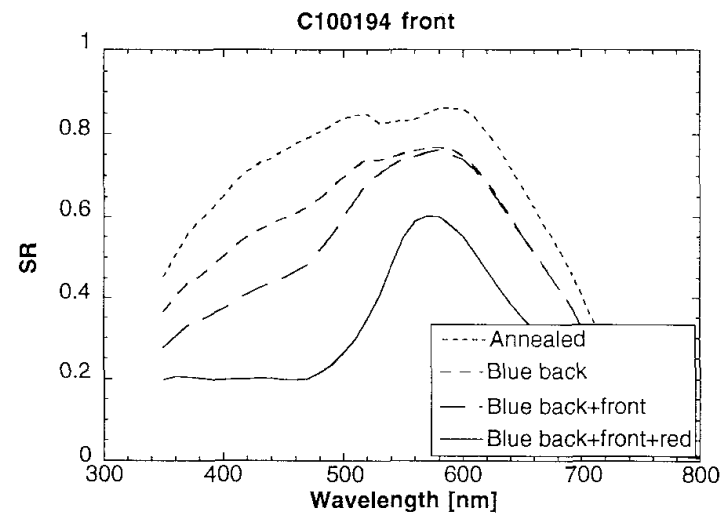

Fig. 6: Spectral response at OV bias voltage, under front illumination without bias light for a $0.5 \mu \mathrm{m}$ thick bifacial cell after each step of degradation (corresponds to Fig. 4a).

\section{CONCLUSIONS}

From extensive characterisation of bifacial a-Si:H solar cells after well defined sequences of degradation steps using alternatively both strongly absorbed and uniformly absorbed light, the authors were able to demonstrate the following points:

1) The stable efficiency of a-Si:H solar cells is controlled mainly by an increase of the deep defect density in the bulk of the i-layer, far from the interface region. This statement remains valid for cell thicknesses down to $0.5 \mu \mathrm{m}$. The interfaces regions may thereby yet play a marginal role.

2) No history effect was observed. The final state of the cell is given by the accumulated time of degradation at the most damaging wavelength (i.e. the wavelength at which the generation of defects far from the interfaces is the most efficient).

3) Combining spectral response measurements (with bias light) with illumination from both front and back side helps one to interpret the cell behaviour. Spectral response without bias light does not reflect the situation of an operating cell.

\section{ACKNOWLEDGEMENTS}

We would like to thank S. Dubail for sample preparation and $D$. Fischer for valuable discussions. This work was supported by the Swiss Federal Office of Energy (OFEN) under contract EF-REN 93(032).

\section{REFERENCES}

[1] C.M. Fortmann, S. Lange, M. Hicks, C.R. Wronski, J. Appl. Phys. 64, 1988, pp. 4219-4222.

[2] W. Herbst, A. Scholz, B. Schröder, H. Oechsner, Proc. of the $23^{\text {rd }}$ IEEE Photovoltaic Specialists Conf., Louisville, 1993, pp. 913-918.

[3] F. Smole, J. Furlan, M. Topic, MRS Symp. Proc. 297, 1993, pp. 631-636

[4] W. Kusian, H. Pfeiderer, AIP Conf. Proc. 234, 1991, pp. 291-297.

[5] N. Wyrsch, H. Keppner, N. Pellaton, Y. Ziegler, A.Shah, Proc of the $11^{\text {th }}$ EC Photovoltaic Solar Energy Conf., Montreux, 1992, pp. 742-745.

[6] H. Curtins, N. Wyrsch, M. Favre, A.V. Shah, Plasma Chem, and Plasma Proc. 7, 1987, pp. 267-273.

[7] N. Wyrsch, D. Fischer, A. Shah, Proc. of the $12^{\text {th }}$ EC Photovoltaic Solar Energy Conf., Amsterdam, 1994, pp. 73-76.

[8] D. Fischer, N. Wyrsch, C.M. Fortmann, A.V. Shah, Proc. of the $23^{\text {rd }}$ IEEE Photovoltaic Specialists Conf., Louisville, 1993, pp. 878-884. 